\title{
A Study on Machining Characteristics of KP4 Steel Using Alumina Coated Insert
}

\author{
Jin-Woo KIM*, Seung-Chul LEE** \\ *Department of Mechanical System Engineering, Chosun University, 375 Seosuk-dong, Dong-gu, Gwangju 501-759, \\ Korea, E-mail: jinu763@chosun.ac.kr \\ **Department of Honam Region Business, Korea Testing Certification, B-605, 958-14, Daechon-dong, Buk-gu, Gwangju, \\ 500-470, Korea, E-mail: cjf9400@gmail.com \\ crossref http://dx.doi.org/10.5755/j01.mech.24.1.20216
}

\section{Introduction}

In today's mold industry, there is a growing demand for precision molds for mass production and molds for wide-variety low-volume production. In addition, due to the recent tendency that consumers prefer neat and smooth appearance, ball nose end-mill processing using high-speed machining gains an increasing favor. Highspeed processing can reduce production cost and time by significantly increasing the Material Removal Rate (MRR), and the injection mold finishing is completed with a parallel tool trajectory typically using the ball nose cutter. The treatment with the high-speed processing eliminates extrusion with the cutting time and minimizes manual work by ensuring more accurate and efficient processing at fast cutting feed. High-Speed Machining (HSM) can process products with thin walls and thus, it is an important process for manufacturing lightweight parts for the aerospace industry that attaches importance to state-of-the-art IT components and light weight [1-6].

On the other hand, a particular feature of the mold industry is that production is determined by the client, not by the manufacturer, even in case of mass-production. Therefore, the distribution channel is simple and the molds of the same shape are seldom repeated. Furthermore, the delivery timeframe is getting ever shorter. In this situation, many domestic manufacturers are considering to introduce high-speed machining to increase time to market. However, since high-speed machining is a new technology, there is a number of concerns in its adoption. Most concerns are related to unfamiliarity with high-speed machining itself, uncertainty about the effects of the machining system, and their adaptability to new technology [7-13].

Chubb et al. [14] found abrasion and diffusion as dominant wear mechanisms on the flank and rake face, respectively, during machining of EN24 steel with TiC coated carbide tools. Jindal et al. [15] evaluated the metal cutting performance of PVD TiN, TiCN, and TiAlN coated cemented carbide tools. Stappen et al. [16] can work as a good compromise between TiAlN and TiCN coatings. Klocke et al. [17] ceramic coating $\mathrm{Al}_{2} \mathrm{O}_{3}$ exhibits good resistance to abrasive wear and has high thermal stability. Haron et al. [18] observed a cutting speed limit of 75 $\mathrm{m} / \mathrm{min}$ when using uncoated carbide inserts for machining tool steel.

\section{Experimental setup and methods}

In this study examine KP4 steel (AISI $4140 \mathrm{im}-$ proved, $\mathrm{H}_{\mathrm{R}} \mathrm{C} 32$ ), a non-thermal treated material among plastic mold steels, a material widely used in the mold industry. On Table 1, chemical compositions are shown. The sample will be machined upwards and downwards at different angles $\left(15^{\circ}, 30^{\circ}, 45^{\circ}\right)$. To this end, this experiment uses a multicoated carbide tool (1 to 4 layers of AlTiN using physical vapor deposition (PVD) and ion plating). This study will present basic processing data of the multi-coated ball end-mill and discuss the characteristics of high-speed machining.

Table 1

Chemical compositions of KP4 steel (AISI 4140 improved)

\begin{tabular}{|c|c|c|c|c|c|}
\hline Elements & $\mathrm{C}$ & $\mathrm{Si}$ & $\mathrm{Mn}$ & $\mathrm{Cr}$ & $\mathrm{Mo}$ \\
\hline \multirow{2}{*}{$\mathrm{wt}, \%$} & 0.26 & 0.15 & 0.80 & 0.90 & 0.20 \\
\cline { 2 - 6 } & 0.43 & 0.35 & 1.15 & 1.50 & 0.30 \\
\hline
\end{tabular}

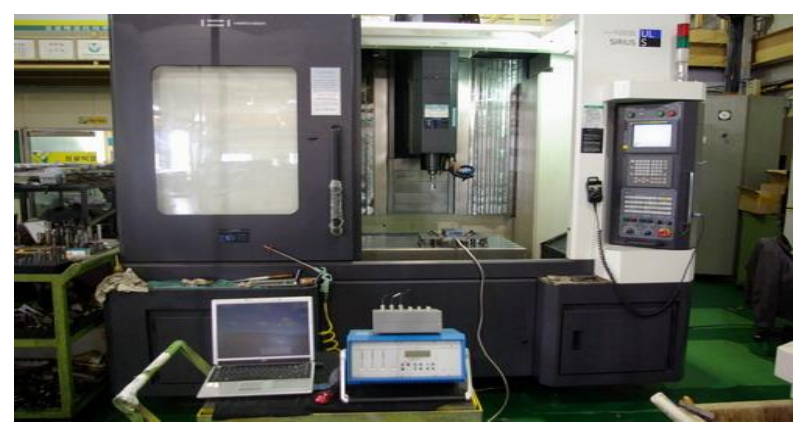

a

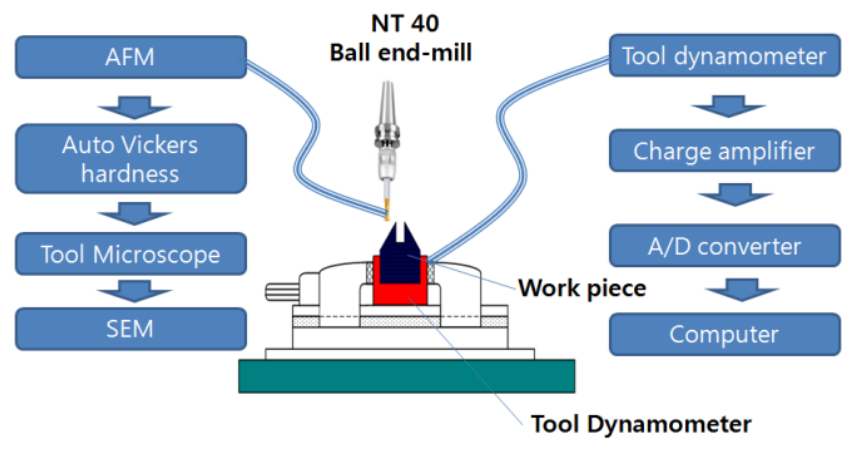

b

Fig. 1 Experimental setup: a - Measurements of machining; b - Schematic diagram 
The machining experiment is conducted using a vertical machining center (Hwa Cheon Sirius- UL (S), August 2008) at highest spindle rotation speed of 20,000 $\mathrm{rpm}$. An overall schematic diagram for the various measuring elements used in this experiment is shown in Fig. 1. The machining force is measured using multichannel charge amplifier (5019b). In order to steadily amplify fine voltage from piezoelectric tool dynamometer (Swiss Kistler, 9257b), and the inclined materials were machined before the experiment.

The roughness of the surface after processing is determined as an average of two measurements made at the middle point between the inclined material and the semicircular material, using a stylus probe type roughness tester (Mitutoyo, BRT-S916). After the carbide ball end-mill is coated with one (1) to four (4) layers of AlTiN, its surface roughness is measured using the Atomic Force Microscope (AFM, PSIA, XE-200), and the hardness of the coated layer is measured using the electronic microhardness tester (Mitutoyo, AAV-50 2). In addition, the cross-sectional structure of the coated layer is examined using a scanning electron microscope (SEM, Jelo, JSM840-A).

The specimen used in this study is made of KP4 steel, which is a non-thermal treated steel material used for automobile bumpers, OA devices, and grills, and processed first at the machining center with $\mathrm{F}$ inclinations $15^{\circ}, 30^{\circ}$ and $45^{\circ}$. The cutting tools used in the experiment is a carbide (Co 12\%, WC + Cr3 + C2 + VC 88\%) $\Phi 8 \mathrm{~mm}$ ball end-mill made by Kong Hwa Precision Tools, coated with 1 to 4 layers of AlTiN using ion plating by physical vapor deposition method.

This study used "Cimatron" CAD/CAM developed by CLAL Computers \& Technologies, Israel, which is the most used in the mold industry along with UG (Unigraphics). It was set up according with the requirements for machining 3D modeling tools. The cutting conditions required for this experiment are set up using "SurfCam" program, US, and forwarded directly to the machining center via data network.

Table 2

Cutting conditions

\begin{tabular}{|c|c|c|c|}
\hline $\begin{array}{c}\text { Plane } \\
\text { angle }\end{array}$ & $\begin{array}{c}\text { Depth of } \\
\text { cut, } \mathrm{mm}\end{array}$ & $\begin{array}{c}\text { Spindle speed, } \\
\mathrm{N}, \mathrm{rpm}\end{array}$ & $\begin{array}{c}\text { Feed rate, } \\
\mathrm{mm} / \mathrm{min}\end{array}$ \\
\hline 15 & 0.3 & 10,000 & 1,300 \\
\hline 30 & 0.6 & 13,000 & 1,500 \\
\hline 45 & 0.9 & 16,000 & 1,700 \\
\hline
\end{tabular}

The cutting conditions for the machining experiment are shown in Table 2, with the same machining parameters except for inclination and machining directions. After measuring surface roughness according to the size, the material is attached to the tool dynamometer undergoes roughing and finishing operations using a $\Phi 10 \mathrm{~mm}$ ball end mill to match the existing operation conditions.

\section{Experiment results and discussions}

\subsection{Analysis of the surface of AlTiN-coated tools}

For measuring the roughness of the coated tool surface, Atomic Force Microscope (AFM) manufactured by PSIA, which can measure specimen surface in $\mathrm{nm}$ range was used. In this experiment, the specimen was scanned by
$20 \times 20 \mu \mathrm{m}$ units, to observe and measure the surface roughness of the tools according to the layers of coating.

As shown in Fig. 2, the surface roughness of the AlTiN coated carbide ball end-mill is indicated by RMS values in the AFM equipment. The RMS shows the size of the waveform in view of the power in angstroms $(\AA)$ unit. Angstrom is a unit of length, and $1 \AA=0.0001 \mu \mathrm{m}$. The RSM values of the coated layers, converted into $\mu \mathrm{m}$, show that the tools with three layers of AlTiN coating demonstrate best results in surface roughness measurement. The thickness of four layers is too thick.

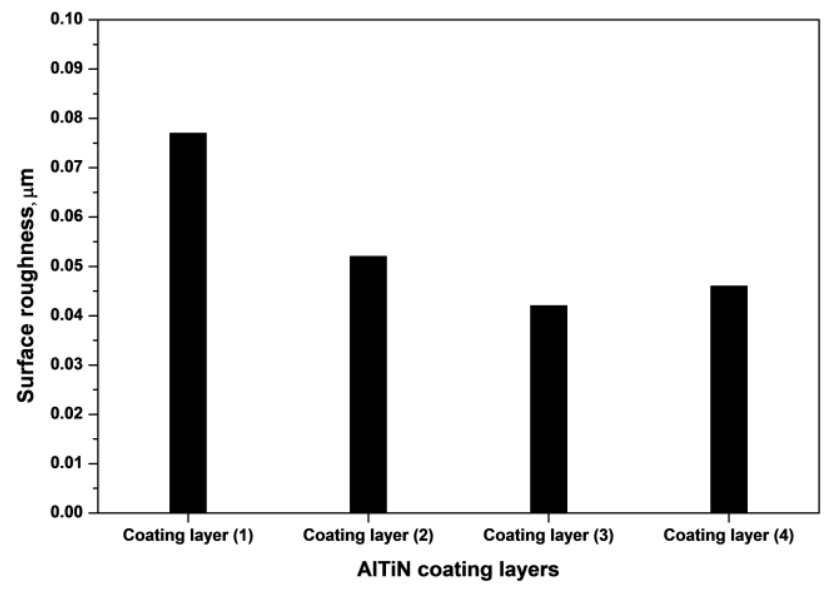

Fig. 2 Surface roughness of AlTiN coating layer measured by AFM

\subsection{Hardness of AlTiN coating layer}

The hardness of the AlTiN coated tools according to the number of layers of coating is measured using an automatic microhardness tester by Mitutoya, which could automatically run a series of tests such as loading, electronic turret, focusing, indentation dimension reading, and moving to the measurement position. Taking into account the depth of the tool coating layer, the test power for the hardness measurement is set to $4.904 \mathrm{~N}$ under $50 \mathrm{x}$ objective lens that can measure the indentation depth of 4 40 $\mu \mathrm{m}$.

The hardness of the AlTiN layers is measured as shown in Table 3, where the hardness of the carbide tool is measured as $18.37 \mathrm{GPa}$ and that of one AlTiN coating layer as $22.84 \mathrm{GPa}$, showing the difference of $4.8 \mathrm{GPa}$. The difference between the hardness of one-layer coating and that of two layers coating is $4.8 \mathrm{GPa}$, while that between two layers and three layers is $2.1 \mathrm{GPa}$ and between three layers and four layers $1.5 \mathrm{GPa}$. The thickness of four layers is too thick. It was found that the more layers of coating the smaller is the difference.

Table 3

Hardness values of AlTiN coating layer

\begin{tabular}{|c|c|}
\hline Tool & Vickers hardness, GPa \\
\hline Carbide Tool & 18.37 \\
AlTiN 1 & 22.84 \\
AlTiN 2 & 27.6 \\
AlTiN 3 & 29.7 \\
AlTiN 4 & 28.22 \\
\hline
\end{tabular}




\subsection{Composition of the AlTiN coating layer}

In this experiment, only tungsten (W), the main ingredient of the carbide tool, and the components of the coating material such as aluminum (Al), titanium (Ti), silicon ( $\mathrm{Si}$ ) and nitrogen $(\mathrm{N})$ identified using SEM-EDX are analyzed as shown in Fig. 3. As shown in Fig. 4, the value for tungsten (W) becomes smaller at the part where coating starts, and the values for the main components of AlTiN coating such as aluminum (Al) and titanium (Ti), which are not present at the carbide, increase where coating starts. For silicon ( $\mathrm{Si})$, it is shown that it is included in the carbide tool in a large quantity, but the quantity is significantly reduced in the coating layer. This result indicates that the value for silicon ( $\mathrm{Si}$ ) is low as the AlTiN coating contains $\mathrm{Al}-58 \%$, Ti-33\% and $\mathrm{Si}+\mathrm{N}-9 \%$. Fig. 4 shows the result of the SEX-DEX composition analysis for aluminum (Al) and titanium (Ti) according to the number of AlTiN coating layers.

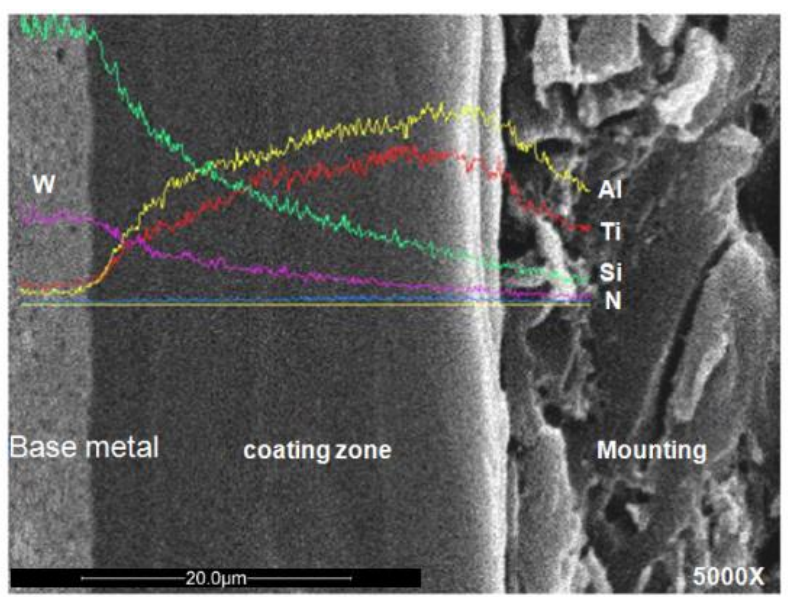

Fig. 3 Quantitative values of the composition of AlTiN coating layer using SEM-EDX

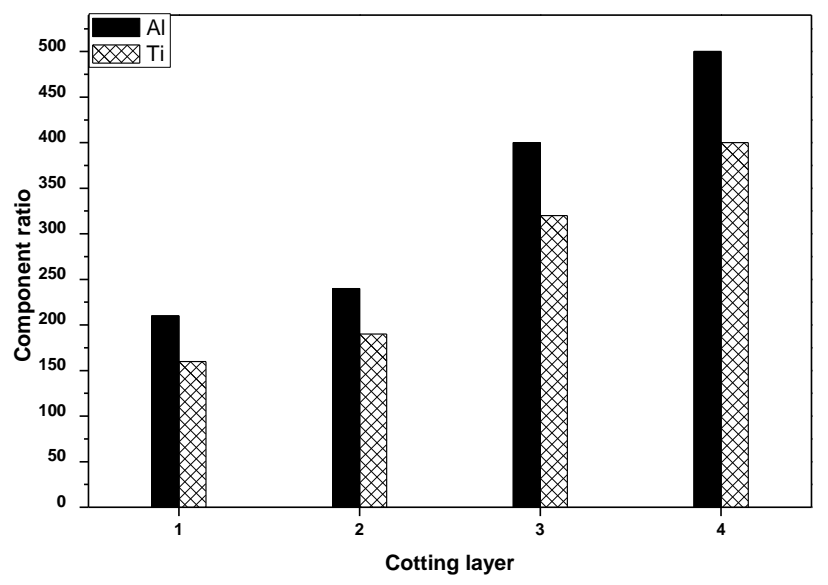

Fig. 4 Composition ratio of $\mathrm{Al}$ and $\mathrm{Ti}$ of the coating tool

3.4 Cutting force of the inclined materials

As shown in Fig. 5, the sizes of three component cutting forces $(F x, F y$ and $F z)$ tend to be higher in downwards direction than upwards under all conditions for each shape, with component force $F z$ higher than the component force $F x$.

The directional difference of component forces during material machining with inclination of $15^{\circ}$ as shown in Fig. 5, a is due to the contact lengths of the ball end-mill, $1.53 \mathrm{~mm}, 2.19 \mathrm{~mm}, 2.71 \mathrm{~mm}$ respectively, for cutting depths $0.3 \mathrm{~mm}, 0.6 \mathrm{~mm}, 0.9 \mathrm{~mm}$, which is $0.06 \mathrm{~mm}$ shorter in downwards direction than in the upwards under all conditions. Also, because the line cutting speed at the center becomes 0 due to "chisel edged" contact in the center of the ball end-mill, the component forces appear to be higher in the downwards direction than in the upwards. As the inclination of the material increases to $30^{\circ}, 45^{\circ}$, the directional difference becomes smaller.

The Bigger inclination angle enables a larger effective diameter of the tool and will induce the application of less force. In the downward direction of machining, the effective diameter of the tool is reduced, and the corresponding cutting component force is larger.

For material with inclination of $30^{\circ}$ as shown in Fig. 5, b, the values of three component forces $(F x, F y$ and $F z$ ) appear to be higher than for material with inclination of $15^{\circ}$, especially in the component force $F x$. It is also shown that directional difference in the cutting component forces is reduced. This phenomenon is observed for all conditions. The contact lengths of the ball end-mill tool with material with inclination of $30^{\circ}$ undercutting depth of $0.3 \mathrm{~mm}, 0.6 \mathrm{~mm}$, and $0.9 \mathrm{~mm}$ is measured respectively as $1.54 \mathrm{~mm}, 2.2 \mathrm{~mm}$ and $2.72 \mathrm{~mm}$ in the upwards direction, and $1.58 \mathrm{~mm}, 2.24 \mathrm{~mm}$ and $2.76 \mathrm{~mm}$, showing $0.04 \mathrm{~mm}$ difference in the tool contact arc length for upward and downward dictions. In addition, compared to the machining conditions for material with inclination of $15^{\circ}$, the tool contact arc length is $0.5 \mathrm{~mm}$ smaller in the upwards direction and $0.05 \mathrm{~mm}$ bigger in the downwards direction.

Fig. 5, c shows that machining of material with inclination of $45^{\circ}$ is characterized by a small difference in three cutting component forces under all conditions, and the difference in cutting component forces between the downward and the upward directions is also small. This can be explained as follows. For material with inclination of $45^{\circ}$, machining proceeds by the tool edge on the tool side of the ball end-mill in the upward direction, while it starts on the side away from "chisel edged" part and ends at the part forming $45^{\circ}$ from the tool center. For this reason, a large component force $F x$ is generated, decreasing the difference in three cutting component forces $(F x, F y$, $F z)$.

\subsection{Cutting force according to the number of AlTiN coat- ing layers}

As shown in Fig. 6, the values of three component forces $(F x, F y, F z)$ according to the number of layers of A1TiN coating on $\Phi 8 \mathrm{~mm}$ carbide ball end-mill are small and stable for the carbide ball end-mill with three layers of coating, as compared to that with four layers of coating. This result was observed for all machining conditions of materials at all inclinations $\left(15^{\circ}, 30^{\circ}, 45^{\circ}\right)$. The cutting forces of the carbide ball end-mill with four layers of AlTiN coating are higher than those for three layers of coating. It is thought that the same reason for the results of the coating surface hardness test and the tool surface roughness test works for the machining test as well. For machining of material with inclination of $45^{\circ}$, the carbide tool with three layers of AlTiN coating shows the component forces $F x$ of $77.33 \mathrm{~N}, F y 78.77 \mathrm{~N}$ and $F z 75.02$ in the upwards direction with such conditions as the cutting depth 
of $0.3 \mathrm{~mm}$, spindle rotation count of 10,000 , and feed rate of $1,500 \mathrm{~mm} / \mathrm{min}$. For machining with the inclinations of $15^{\circ}$ and $30^{\circ}$, the tool with three layers of coating shows the best component force values of cutting.

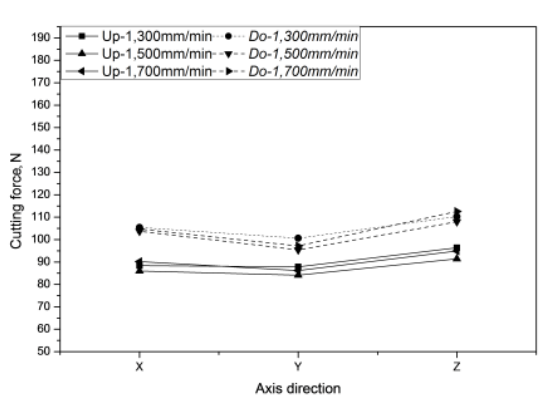

a

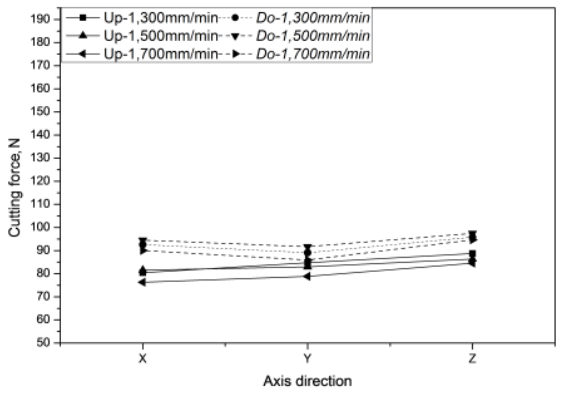

b

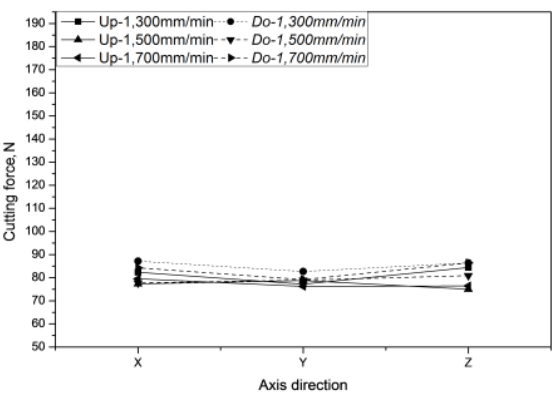

c

Fig. 5 Three component forces $(F x, F y, F z)$ of cutting the material of inclination according to AlTiN coating layer: a - Inclination of $15^{\circ}$ angle; $b$ - Inclination of $30^{\circ}$ angle; c - Inclination of $45^{\circ}$ angle

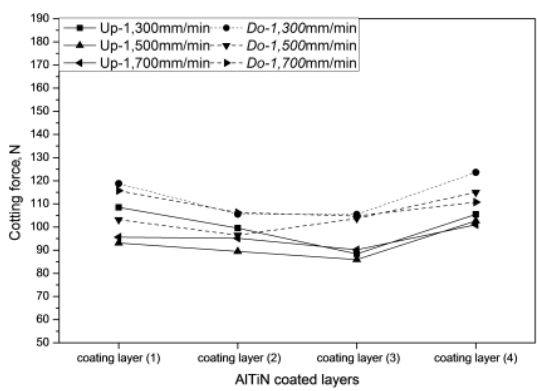

a

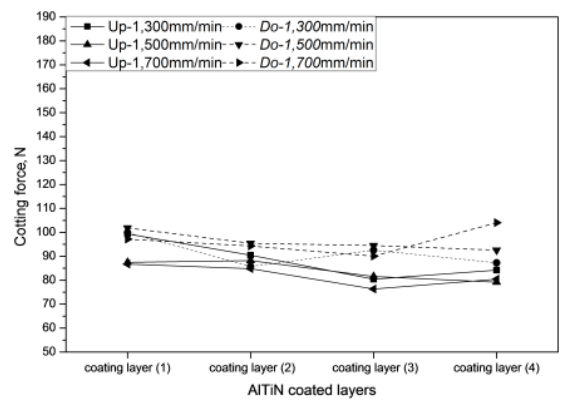

b

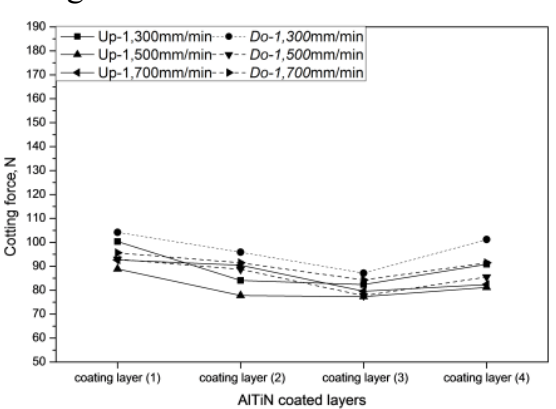

C

Fig. $6 F x$ component force with the material of inclination according to AlTiN coating layer: a - Inclination of $15^{\circ}$ angle; $\mathrm{b}$ - Inclination of $30^{\circ}$ angle; $\mathrm{c}$ - Inclination of $45^{\circ}$ angle

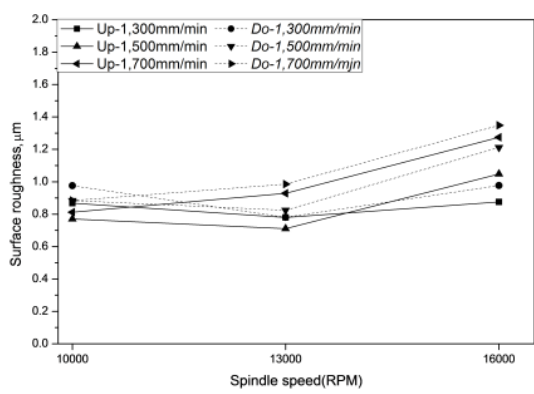

a

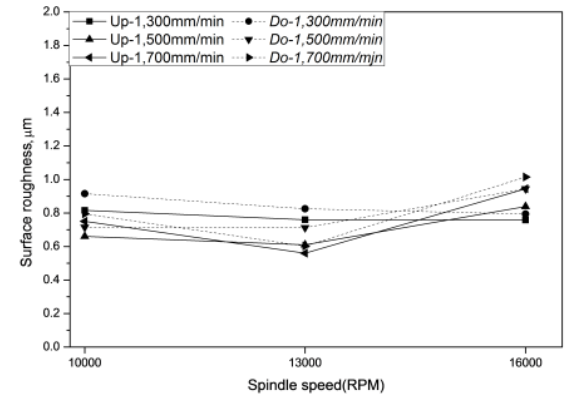

b

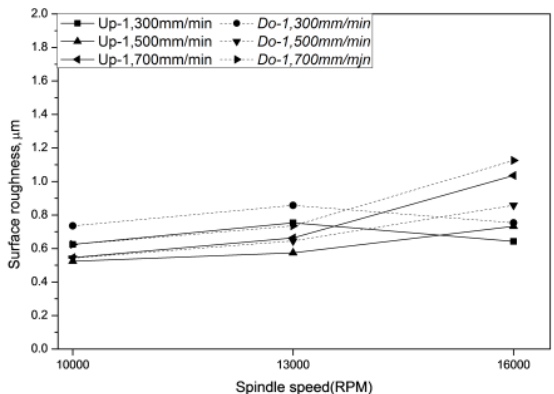

c

Fig. 7 Results of surface roughness for AlTiN coating layer and material with $15^{\circ}$ of inclination according to cutting conditions $(\mathrm{d}=0.3 \mathrm{~mm})$ : $\mathrm{a}$ - Inclination of $15^{\circ}$ angle; $\mathrm{b}$ - Inclination of $30^{\circ}$ angle; $\mathrm{c}$ - Inclination of $45^{\circ}$ angle

3.6. Surface roughness of the material depending on inclination

Machining precision and surface roughness during molding and machining are dependent on the tool. Even with the use of the same machine, erosion, the condition of the cutting tool, composition, habit, surroundings, etc., alter the results. A relative motion between tool and article will occur during machining and results in the shape and face of the article

As the shape of the machined material for the experiment was not flat but inclined, $-\mathrm{X}$ and $-\mathrm{Y}$ stages is set up on the granite plate of the roughness tester, the angle plate is fixed on the stage to adjust the angle to ensure accurate measurement of the surface roughness of the inclined material. The surface roughness meter used in the experiment is a stylus probe type tester with the measuring range of $12 \mathrm{~mm}$ and the cut off $0.8 \mathrm{~mm}$.

The surface roughness of the inclined material was found to become larger as the cutting depth increases but reduces with inclination. As shown in Fig. 7, a, the surface roughness of the material with inclination of $15^{\circ}$ is the lowest $(R a 0.66 \mu \mathrm{m})$ at spindle rotation speed of 13,000 $\mathrm{rpm}$ and the tool feeds speed of $1,500 \mathrm{~mm} / \mathrm{min}$. Fig. $7, \mathrm{~b}$ shows that of the one with inclination of $30^{\circ}$ be the lowest being $R a 0.56 \mu \mathrm{m}$ at the spindle rotation speed of 13,000 $\mathrm{rpm}$ and the tool feed speed of $1,700 \mathrm{~mm} / \mathrm{min}$; and in Fig. 7, c, that of the one with the inclination of $45^{\circ}$ be the lowest being $R a 0.52 \mu \mathrm{m}$ at the spindle rotation speed of $10,000 \mathrm{rpm}$ and the tool feed speed of $1,500 \mathrm{~mm} / \mathrm{min}$. 


\section{Conclusions}

In this study, KP4 steel, a non-thermal treated material among plastic mold steels, was machined at inclinations of $15^{\circ}, 30^{\circ}$ and $45^{\circ}$, using $\Phi 8 \mathrm{~mm}$ carbide ball endmill with one to four layers of AlTiN coating, to examine cutting component forces and surface roughness according to the number of coating layers. The following conclusions were made.

1. Mechanical properties of the specimen are found to be the best when the carbide ball end-mill was coated in three layers, with the hardness of the coating layer being Hv 3027.3 and surface roughness $0.042 \mu \mathrm{m}$.

2 . The cutting component forces are better in the upwards direction than in downwards, and become smaller as the effective diameter of the tool increases as the angle of inclination of the material got bigger.

3. The surface roughness was better in the upwards direction, and it is the best when the tool with three layers of AlTiN coating is used.

\section{Acknowledgments}

This study was supported by the research fund from Chosun University (2016).

\section{References}

1. Belforte, G.; Colombo, F.; Raparelli, T.; Trivella, A.; Viktorov, V. 2013. Experimental Analysis of Air Pads with Micro Holes, Tribology Transactions, 56(2): 169-177. http://dx.doi.org/10.1080/10402004.2012.734547.

2. Kim, D. W.; Lee, Y. S.; Park, M. S.; Chu, C. N. 2009. Tool life improvement by peck drilling and thrust force monitoring during deep-micro-hole drilling of steel, International Journal of Machine Tools and Manufacture 49: 246-255.

https://doi.org/10.1016/j.ijmachtools.2008.11.005.

3. Kim, G. D.; Loh, B. G. 2011. Direct Machining of Micro Patterns on Nickel Alloy and Mold Steel by Vibration Assisted Cutting, International Journal of Precision Engineering and Manufacturing 12 (4): 583-588. http://dx.doi.org/ 10.1007/s12541-011-0075-y.

4. Chun, S. H.; Ko, T. J. 2011. Study on the response surface model of machining error in internal lathe boring, International Journal of Precision Engineering and Manufacturing 12 (2): $177-182$. http://dx.doi.org/ 10.1007/s12541-011-0025-8.

5. Biermann, D.; Kahleyss, F.; Krebs, E.; Upmeier, T. 2011. A study on micro-machining technology for the machining of NiTi: five-axis micro-milling and micro deep-hole drilling, Journal of Materials Engineering and Performance 20 (4-5): 745 - 751.

http://dx.doi.org/ 10.1007/s11665-010-9796-9.

6. Fan, Z. W.; Hourng, L. W. 2011. Electrochemical micro-drilling of deep holes by rotational cathode tools, Journal of Advanced Manufacturing Technology 52 (58): $555-563$. http://dx.doi.org/ 10.1007/s00170-010-2744-x.

7. Neo, K. S.; Rahman, M.; Li, X. P.; Khoo, H. H.; Sawa, M.; Maeda, Y. 2003. Performance evaluation of pure CBN tools for machining of steel, Journal of Materials Processing Technology 140 (1-3): 326-331.
https://doi.org/10.1016/S0924-0136(03)00746-5.

8. Abbas, A. T. M. 2012. Enhanced CnC machines capabilities by adding circular patterns cycle. International Journal of Precision Engineering and Manufacturing 13 (10): $1753-1758$. http://dx.doi.org/ 10.1007/s12541-012-0230-0.

9. Gilbin, A.; Fontaine, M.; Michel, G.; Thibaud, S. Picard, P. 2013. Capability of tungsten carbide micromills to machine hardened tool steel. International Journal of Precision Engineering and Manufacturing 14 (1): $23-28$.

http://dx.doi.org/ 10.1007/s12541-013-0004-3.

10. Helen, C., Richard, W., Martin, P., Philip, K., Richard, D., David, A. 2003. Rapid machining of hardened AISI H13 and D2 moulds, dies and press tools, Journal of Materials Processing Technology 135 (2-3): $301-$ 311. https://doi.org/10.1016/S0924-0136(02)00861-0.

11. Sen, M., Shan, H. S. 2005. A review of electrochemical macro-to micro-hole drilling processes. International Journal of Machine Tools and Manufacture 45: $137-152$. https://doi.org/10.1016/j.ijmachtools.2004.08.005.

12. Park, C. H., Song, C. K., Hwang, J. H., Kim, B. S. 2009. Development of an ultra precision machine tool for micromachining on large surfaces. International Journal of Precision Engineering and Manufacturing 10 (4): 85-91. http://dx.doi.org/ 10.1007/s12541-009-0075-3.

13. Dewes, R. C.; Ng, E.; Chua, K. S.; Newton, P. G.; Aspinwall, D., K. 1999. Temperature measurement when high speed machining hardened moul/die steel, Journal of Materials Processing Technology 92/93: $293-268$. https://doi.org/10.1016/S0924-0136(99)00116-8.

14. Chubb, J.; Billingham J, J. 1980. Coated cutting tools- A study of wear mechanisms in high speed machining. Wear 61: 283-293. https://doi.org/10.1016/0043-1648(80)90292-6.

15. Jindal, P. C.; Santhanam, A. T.; Schleinkofer, U.; Shuster, A. F. 1999. Performance of PVD TiN, TiCN, and TiAlN coated cemented carbide tools in turning, International Journal of Refractory Metals \& Hard Materials 17: 163-170. https://doi.org/10.1016/S0263-4368(99)00008-6.

16. Stappen, V. M.; Stals, L. M.; Kerkhofs, M.; Quaeyhaaegens, C. 1995. State of the art for the industrial use of ceramic PVD coatings, Surface and Coatings Technology 74-75 (2): 629-633. https://doi.org/10.1016/0257-8972(95)08296-4.

17. Klocke, F.; Kreig, T. 1999. Coated tools for metal cutting -Features and Applications. Annals of the CIRP, 48 (2): 515-525. https://doi.org/10.1016/S0007-8506(07)63231-4.

18. Haron, C. H.; Che Ginting, A.; Goh, J. H. 2001. Wear of coated and uncoated carbides in turning tool steel, Journal of Materials Processing Technology 116: 49-54. https://doi.org/10.1016/S0924-0136(01)00841-X. 


\section{Jin-Woo KIM, Seung-Chul LEE}

\section{A STUDY ON MACHINING CHARACTERISTICS OF KP4 STEEL USING ALUMINA COATED INSERT}

\section{S u m m a r y}

In this study examine KP4 steel (HRC 32), a nonthermal treated material among plastic mold steels, a material widely used in the mold industry. The sample will be machined upwards and downwards at different angles $\left(15^{\circ}\right.$, $\left.30^{\circ}, 45^{\circ}\right)$. To this end, it uses a multicoated carbide tool (1 to 4 layers of AlTiN using physical vapor deposition (PVD) and ion plating). This study presents basic processing data of the multi-coated ball end-mill and discuss the characteristics of high-speed machining. For measuring the roughness of the coated tool surface, this study uses Atomic Force Microscope (AFM) manufactured by PSIA, which can measure specimen surface in $\mathrm{nm}$ range. In this experiment, the specimen was scanned by $20 \times 20 \mu \mathrm{m}$ units, to observe and measure the surface roughness of the tools according to the layers of coating. Mechanical properties of the specimen are found to be the best when the carbide ball end-mill is coated in three layers, with the hardness of the coating layer being $29.7 \mathrm{GPa}$ and surface roughness $0.042 \mu \mathrm{m}$. The cutting component forces are better in the upwards direction than in downwards, and become smaller as the effective diameter of the tool increases as the angle of inclination of the material got bigger.

Keywords: Cutting component force, KP4 steel (plastic mold steel), surface roughness, ball end mill.

Received January 04, 2017 Accepted February 15, 2018 